\title{
7) El surgimiento de los comedores escolares en la Pampa en crisis
}

\author{
María José Billorou ${ }^{1}$
}

as políticas de protección a la infancia, originariamente urbanas, -tuvieron como objetivo, en un primer momento, la reducción de la mortalidad infantil pero además se encaminaron a responder a los desafíos de la presencia creciente de niños en su seno. Así, se perfiló una nueva concepción de la niñez que remarcaba su diferenciación con el mundo adulto. Esta concepción estaba afianzada mucho más en Argentina, en las áreas del litoral: a principios de siglo, las áreas del interior parecían estar aisladas de estas iniciativas debido a una visión benéfica e idílica de su entorno que las asociaba con ausencia de enfermedades y patologías.

En los primeros años de la década del treinta, paulatinamente, estas ideas llegaron al interior del país, como respuestas para enfrentar los cambios acaecidos en la dinámica económica y social. Especialmente, el Territorio Nacional de La Pampa fue afectado por una dura crisis agroclimática, una sequía prolongada, que se sumó a los cambios en los mercados internacionales de productos primarios y perjudicó a las áreas rurales. Ambos fenómenos generaron una significativa pérdida demográfica; de esta manera, muchas áreas rurales se despoblaron al mismo tiempo que las metrópolis del Litoral incrementaron su población de manera explosiva.

La crisis impulsó la necesidad concreta del accionar público en la asistencia social, especialmente sobre los sectores populares a partir de la instauración instituciones específicas de protección a la infancia, del afianzamiento de la profesión médica y de una mayor presencia sanitaria en las instituciones educativas.

1 Instituto de Estudios Socio-Históricos. Facultad de Ciencias Humanas. Universidad Nacional de La Pampa. Estetrabajo integra el proyecto “Sociedad, economía, población, política y religión en La Pampa. Un abordaje histórico (sigl os XIX-XX)". 
Maríaj oséBillorou

Este trabajo busca analizar el surgimiento de una red de instituciones, cuyo accionar se basó en la protección y la defensa de la infancia más vulnerable, los comedores escolares, en tanto nos permite develar el protagonismo de los distintos agentes estatales, las relaciones suscitadas entre las diferentes jurisdicciones - nacional, provincial y municipal- así como el papel de la comunidad en la ejecución concreta de políticas públicas.

Para ello, en su primera parte, se aborda el surgimiento de la importancia de la alimentación escolar infantil y su inclusión dentro del entramado institucional estatal, tanto en el ámbito internacional como en el nacional. Luego se examina su implementación en una región específica, el Territorio Nacional de la Pampa, especialmente a través del análisis de los comedores que funcionaban en las escuelas de las localidades de Anguil y Guatraché. Finalmente, se abordan las limitaciones sobre las cuales se construyeron las políticas nacionales para la protección y asistencia de los alumnos, a partir del surgimiento de la Comisión Nacional de Ayuda Escolar.

\section{Los comedores escolares: "el deseo de reparar los funestos efectos producidos en los niños por la insuficiencia de la alimentación"}

La relación entre salud y educación se manifestó en los orígenes del sistema educativo; así la ley 1420, constituyente de la estructura educativa argentina, preveía en su articulado que la instrucción debía estar acorde a la higiene (D i Liscia 2004:39).

Esta lógica organizativa posibilitó que el discurso médico higienista impactara en la escuela, especialmente partir de la elaboración de los programas y de los textos escolares, los cuales transmitieron una representación del cuerpo y de los saberes acerca de él. De esta manera, las instituciones educativas y el colectivo médico generaron un estrecho vínculo que les permitió desarrollar su función específica. La estructura educativa utilizó el andamiaje teórico del higienismo para divulgar a través de la enseñanza, hábitos, rutinas y conductas orientadas al cuidado de la salud y el cuerpo. Al mismo tiempo, los médicos higienistas, intentaron monopolizar la mayor cantidad de instituciones estatales posibles, entre las cuales privilegiaron las escolares, para 
transmitir su credo científico. El saber higienista ${ }^{2}$ buscó enseñar más que conocimientos anatómico-fisiológico sobre el cuerpo, imponer prácticas reguladoras sobre las conductas tanto individual es como sociales (Lionetti 2007).

Por lo tanto, esta vigorosa relación entre educación e higiene, a finales del siglo XIX, impulsó la creación de agencias específicas. En 1888, se estableció en forma definitiva, el Cuerpo Médico Escolar. Su presencia buscaba tanto garantizar la vigilancia de las normas higiénicas institucionales así como el control de la salud de docentes y alumnos. Esta última función lo invistió de un poder notable dentro de la vida escolar: la certificación de buena salud, indispensable para ingresar y permanecer en los diferentes niveles del sistema tanto alumnos como docentes (Lionetti 2007). Sin embargo, más allá de los amplios objetivos planteados para estos funcionarios nacionales, sus acciones se limitaron a la ciudad de Buenos Aires. En gran medida, esta situación se debió a la escasez de personal; entre 1899 y 1902, la planta del cuerpo Médico escolar estaba constituida por un director y nueve médicos, insuficiente aún para atender la salud de los escolares porteños, más de 500.000. Recién en 1915, cada uno de los veinte consejos escolares de la ciudad contó con un médico escolar. Claramente, las posibilidades de ejercer sus funciones sobre la población escolar de las provincias y territorios, eran casi utópicas (Di Liscia 2004:41-42). La creación del cuerpo de Visitadoras de Higiene Escolar ${ }^{3}$ en 1929 amplió el personal disponible con la integración de personal auxiliar dedicado fundamentalmente a las funciones de asistencia educativa y social. Las visitadoras actuaban como eficaces intermediarias entre médicos y familias. A través de su acción, buscaban lograr un contacto permanente y continuo con aquellos niños cuyo crecimiento se encontraba más alejado de la supervisión y el control médico.

2 El higienismo elaboró un discurso médico-científico que legitimó prácticas modernizadoras a la vez que disciplinarias del cuerpo social (ver Armus 2000).

3 La higiene social y el interés en el cui dado infantil generaron una nueva carrera para las mujeres como visitadoras sociales. En 1925 se creó, el Curso de Visitadoras de Higiene Social, en el Instituto deHigiene dela Facultad deCiencias Médicas delaUniversidad de BuenosAires. Los espacios de acción privil egiados para las Visitadoras, se instauraron especial mente en los establecimientos estatales tanto médicos, asistenciales como los escolares; de esta manera la lucha antitubercul osa, la protección a la infancia y la asistencia escolar se desplegaron como rumbos iniciales para la profesión. Se puntualizaron exigencias particulares para certificar desempeños específicos, para el curso de Visitadora de Tuberculosis, se exigió la condición de enfermera o servicios documentados de asistencia a enfermos y para el curso de Visitadora Escolar, el título de maestra normal. 
El desarrollo institucional y profesional consolidó una especificidad en los conocimientos médicos; la higiene escolar que se ocupaba "de todos los factores" que influían "sobre la salud o el desarrollo físico y psíquico del niño escolar." De esta manera, no sólo se preocupaba "del crecimiento y alimentación así como combate las enfermedades propias de este período de la vida" sino que incorporaba como parte constitutiva de su saberes y acciones el "desarrollo psíquico e higiene mental del niño" (Casanave 1995:285). Por lo tanto, la higiene del escolar, tendía no sólo a la "salud corporal" y a la "espiritual" sino también indicaba "las medidas preventivas de las enfermedades" que amenazaban a la población escolar y determinaba "Ios medios apropiados para asegurar el desarrollo del cuerpo y el descanso de la inteligencia" (Rodríguez 1955:211).

De esta manera, el discurso médico, señalaba rotundamente el crecimiento y la nutrición como uno de los núcleos básicos del desarrollo de la higiene escolar. La "alimentación insuficiente" se diagnosticaba como la causa principal de la "desnutrición"; por lo tanto, un "niño mal nutrido" tenía grandes posibilidades de convertirse "en una persona inhábil e imposibilitada, incapaz de resistir enfermedades 0 de soportar su ataque y su curso". Así, se instituyó un enemigo a derrotar, la alimentación inadecuada y deficiente cuyos "efectos malignos" repercutían "tanto en el desarrollo físico como en el desarrollo intelectual y moral del niño" (Rodríguez 1955: 228).

Estas ideas sustentaron y legitimaron una serie de iniciativas en pos de mejorar la alimentación de los escolares. En 1906, en la ciudad de Buenos Aires, la escuela 14 del distrito escolar $N$ o 1 estableció la "copa de leche" a instancias de su directora, la Srta. Albertina Pons ${ }^{4}$ y el Dr. Genaro Sisto ${ }^{5}$. Así, comenzó la distribución de un vaso de leche

4 Albertina Pons de Faucheux (1872-1952). Se graduó como maestra en la Escuela Normal de Concepción del Uruguay y como profesora en la de Paraná. En 1891 dictó cátedras en el Colegio Nacional deConcepción del Uruguay, al mismo tiempo que fuevice-di rectora dela escuela de varones. Un año más tarde publicó la revista escolar Estudio y Recreo. Desde 1901 hasta 1910 dirigió la escuela № 9 del consejo escolar VII en la ciudad de Buenos Aires. Volvió a Paraná donde dirigió durante veinteaños la escuela "25 de Mayo". En 1915, fundó la Sociedad Amigos de la Educación (Sosa de Newton 1986:506).

5 Genaro Sisto (1870-1923) Se graduó en la Facul tad de Medicina en 1895 con medal la de oro. Higienista, especial mente interesado en la Higiene Escolar, implementó una serie de iniciativas en pos de la consecución de una niñez sana, entre otras, el horario alterno en las escuelas, la fundación de los Establecimientos preventivos de hi giene infantil y de las colonias de vacaciones en el mar y la montaña. Es autor de numerosos trabajos publicados en libros, folletos y revistas. 
por día a los alumnos. Dos años después, se instaló una experiencia similar en la ciudad de Rosario, Santa Fe. Al mismo tiempo, con el mismo objetivo surgió la "miga de pan" que entregaba un panecillo junto al vaso de leche. El fin de suministrar comidas adicionales, a veces, un desayuno, otras veces, una refección ligera en la mañana, lo constituía la prevención de la desnutrición. Recién en 1914, se incluyó por primera vez en el presupuesto del Consejo Nacional de Educación una partida anual para alimentación en las escuelas de Capital Federal y Territorios $\mathrm{N}$ acionales.

El cuerpo médico escolar, dirigido por el Dr. Enrique O livieri, realizó desde 1924, investigaciones sobre el estado nutricional de los escolares porteños. Los resultados hacia 1925 fueron alarmantes: sobre 200.000 escolares, un $15 \%$ se encontraba insuficientemente alimentado y un 3\% desnutrido. En 1926, se evaluaron la totalidad de los niños concurrentes a las escuelas públicas de la ciudad de Buenos Aires. Los resultados, muy similares al año anterior, hicieron imprescindible la creación de instituciones más complejas para asistir esta situación (Britos, O 'D onnel, U galde y Clacheo 2003:15).

Así surgieron las cantinas escolares, en ellas se les proporcionaba a los niños algunos alimentos, como una copa de leche, un plato de sopa o un panecillo (Casanave 1950:288). Las primeras seis, instituciones dependientes del cuerpo médico escolar, se habilitaron en 1928, cada una podía brindar estos alimentos complementarios a trescientos niños. Sin embargo, los estudios realizados por los médicos escolares en colaboración con las visitadoras de higiene escolar, presentaban aún un panorama bastante sombrío; a pesar de que las cifras habían disminuido no lo habían hecho, en un porcentaje destacado. De un total "de 215.000 niños", $30.412(14 \%)$ Ilegaban a las aulas "con una alimentación insuficiente" y 4.268 (2\%) "no habían tomado en sus hogares alimentación alguna". El número de cantinas escolares, creció para dar respuestas a las necesidades detectadas; sumaban hacia 1930, cuarenta y seis, que atendían un total de 13. 800 niños. Conjuntamente, en la ciudad de Buenos Aires, "la copa de leche" y la "miga de pan", se había generalizado, así, los recibían "230.00 niños o sea la totalidad de los concurrentes a las escuelas fiscales" (O livieri 1931:852).

Esta red asistencial escolar, se complementó, desde inicios del siglo, con la acción de las "escuelas al aire libre". Impulsadas por el cuerpo médico escolar y notorios higienistas como Emilio Coni, Gena- 
ro Sisto y Augusto Bunge, su implementación efectiva y generalizada, de debió a la acción del Dr. José María Ramos M ejía en el Consejo Nacional de Educación. Este médico activo defensor de las ideas eugenésicas que consideraban tanto la herencia como el ambiente y la nacionalidad, como elementos claves de la salud de la población, se convirtió en el gestor de las nuevas instituciones (Lionetti 2007:277). La teoría eugenésica fue elaborada por Francis Galton a fines del siglo $X I X$, quien la consideró como la ciencia del mejoramiento del linaje. Galton sostuvo la importancia de la herencia en la obtención de todos los caracteres de los seres vivientes, de manera que la influencia del medio resultaba mínima en el desarrollo de los individuos. Por lo tanto, los seres humanos heredaban los caracteres físicos, mentales y morales de los padres y los ancestros. U na buena educación o una buena situación podían mejorar la inteligencia, pero lo importante estaba en una buena dotación hereditaria. La finalidad de la eugenesia, entonces, era utilizar todos los medios que puedan razonablemente utilizarse para hacer que las clases más útiles para la comunidad contribuyan más que lo que es su proporción a la siguiente generación ${ }^{6}$ (García González y Álvarez Peláez1999: XXIII-XXIV).

Las escuelas desarrollaban sus actividades de septiembre a mayo, en espacios verdes de la ciudad, las dos primeras funcionaron en 1912, en el Parque Lezama y en el Parque Avellaneda; atendieron, según los años, entre setecientos a mil niños. Sus prácticas apuntaban al fortalecimiento del cuerpo, el contacto intenso con el aire y el sol, el desarrollo de hábitos cotidianos de disciplina, higiene personal y conducta y una alimentación adecuada. La educación formal no era prioritaria, en tanto se la concebía como imposible hasta que no se lograra la recuperación fisiológica del niño (Armus 2007:97-98). Para 1931, el director del cuerpo médico escolar, el Dr. Enrique Olivieri estimaba en "cinco mil", los niños concurrentes a estas instituciones (Olivieri 1931:852). Finalmente, se integró a este entramado de instituciones de alimentación escolar, la Clínica de Nutrición, dentro de la estructura educativa sanitaria, cuya función era "Ia educación sanitaria de la población" (Bazán y Ruiz Moreno 1939:1161).

6 El abordaje de la teoría eugenésica provocó una distinción entre los diferentes al cances desarrollados por los países anglosajones y latinos en su conceptualización e implementación (Stephan 1991). Este anál isis actual mente es discutido por una serie de trabajos (Ver Miranda y Vallejo 2005). 
Sin embargo, más allá de esta relación cimentada entre instituciones escolares y alimentación adecuada; tanto los grandes conflictos en el período entreguerras así como la crisis económica mundial iniciada en 1929, dibujaron un nuevo escenario en el que la producción de alimentos y su distribución comenzaron a convertirse en elementos claves para la estabilidad política, el comercio internacional y las políticas sanitarias. Así, se difundió una nueva cultura de la nutrición que se insertó dentro del proceso de surgimiento de la medicina social y la higiene positiva, donde se combinaba la preocupación por la salud, la plenitud física y la perfección moral. La alimentación adquirió un efecto civilizador sobre trabajadores, campesinos, madres e hijos; así aspiró a difundirse desde el laboratorio a la escuela y el hogar. En torno de la alimentación así como de la fisiología de la nutrición se concentraron políticas internacionales a partir de un ambicioso programa del Comité de Higiene de la Sociedad de las Naciones ${ }^{7}$. Las Escuelas $\mathrm{N}$ acionales de Sanidad y los Institutos de Alimentación fueron los encargados de aplicar esta propuesta internacional en cada realidad nacional (Barona Vilar 2008:265-266).

La ciudad de Buenos Aires no estuvo aislada de este proceso internacional; a la luz de estas ideas, en 1928, se creó el Instituto Municipal de Nutrición dependiente de la Asistencia Pública en el Hospital Rawson $^{8}$ bajo la dirección del Dr. Pedro Escudero ${ }^{9}$. Introdujo diferentes actividades tanto de investigación como de enseñanza, entre las que se destacaron, la organización de la Escuela M unicipal de Dietistas ${ }^{10}$ así como el curso Superior de médicos Dietólogos. Al mismo tiempo, el Instituto buscó a través de acciones de educación y propaganda di-

7 La Organisation d' Hygiène de la Sociedad de las Naciones, formada en 1919, estaba integrada por un Consejo, un Comité de Higiene y un Secretariado. Las condiciones imperantes en Europa, donde la mortalidad infantil y la desnutrición se convirtieron en un problema urgente, guiaron las acciones a seguir. Desde finales de 1920, el Comité, estableció una Comisión Consultiva sobre nutrición que se abocó al tema hasta la II Guerra Mundial.

8 En 1935, se independiza del ámbito hospitalario y se traslada a predios compartidos con el Instituto Pasteur en el Parque del Centenario de la Ciudad de Buenos Aires.

9 Pedro Escudero (1877-1963): graduado en 1902. Pionero de los estudios nutricionales en el país. J efe de Clínica Médica en el Hospital Rawson. Entre 1938 y 1945, fue Profesor Titular de Clínica de la Nutrición en la Facultad de Medicina de la Universidad de Buenos Aires. En 1928, creó el Instituto Municipal de Nutrición. Miembro de numerosas organizaciones, Secretario General del Círculo Médico Argentino y Secretario de Redacción de Anales y de Argentina Médica. Autor de numerosas obras entre las que se destacaron Conferencias sobre Clínica Médica y Etiol ogía de la aortititis (Encicl opedia Visual delaArgentina, 2002:519).

10 El Concejo Deliberante, la instituyó el 20 de Octubre de 1933, mediante Ordenanza № 4961. 
vulgar los principios básicos de una alimentación adecuada y correcta para un óptimo crecimiento infantil; en consecuencia, en 1932, preparó una Cartilla Dietética que distribuyó en todas las escuelas del país.

El Poder Ejecutivo de la Nación, como forma de reconocimiento de la labor desarrollada y en pos de una mejor sintonía con las políticas internacionales nacionalizó en 1938 el Instituto. De esta manera, se establecía un instrumento eficaz para abordar todos los problemas alimentarios que afectaban la sociedad argentina. El médico, Pedro Escudero inició una serie de estudios sobre la realidad completa del país, más allá de la experiencia concreta obtenida en la ciudad de Buenos Aires.

En consecuencia, se dedicó a examinar a los conscriptos, de esta manera, descubrió que 500.000 padecían "minoración física". La "tragedia del país" comenzaba al traspasar "los deslindes de nuestra ciudad" y se develaba en "la disminución biológica por hambre crónica" (Escudero 1940:335). El trabajo adquirió, de ahora en más, una dimensión espacial mayor; en pos de este objetivo, visitó diferentes poblaciones del interior para realizar un informe del estado nutricional de los escolares en todas las provincias. Así, durante una gira realizada por el norte de la provincia de Córdoba, juzgó la situación de ochenta escolares en la localidad de Serrezuela; sólo catorce (17,5\%) demostraban un "estado satisfactorio de nutrición" mientras los restantes, sesenta y seis, $(82,5 \%)$ constituían un "exponente acabado de pauperismo infantil"11.

Simultáneamente, realizó un análisis del costo de vida en la ciudad de Buenos Aires que incluía como elementos centrales el alquiler y la alimentación. Este último ítem fue analizado con especial atención, a través de una encuesta para "determinar la relación entre el presupuesto de la familia, el tipo de alimentación consumida y el estado de la salud" (Escudero 1938-39:8). Este examen fue realizado por las egresadas de la Escuela de Servicio Social del Museo Social Argentino entre el 1 de julio de 1936 y el 30 de noviembre de 1937. Sus conclusiones señalaron que "la gran mayoría de los hogares cuyas entradas diarias por persona fluctúan entre $0,10 \$$ a $1 \$$, invierten más del 50\% en alimentación" (Escudero 1938-39:136).

Las investigaciones del Dr. Pedro Escudero develaron un panorama de pobreza y desnutrición en todo el territorio argentino. El colectivo médico intentó dar respuestas a estas situaciones; sostuvo la nece-

11 La Capital, 23 de noviembre de 1938. 
sidad de que el niño "durante el período escolar, como en la segunda infancia" tomara "una ración suplementaria de crecimiento, además de lo que le corresponde a su peso". Particularmente, lo conmovió la situación de los escolares del interior porque para asistir a clase, estos alumnos de "las escuelas rurales" debían levantarse "temprano", a lo que se sumaba que su almuerzo era tardío, "de modo que entre el desayuno, tomado casi siempre a la ligera, y el almuerzo", mediaban "más de cinco o seis horas". El escenario, se complicaba más al considerar, "las distancias a recorrer para ir a la escuela" (Casanave 1950:287).

El estado nacional, paulatinamente, generó acciones tendientes a formalizar políticas públicas. En primer lugar, en 1932, las cantinas maternales fueron reemplazadas por comedores ${ }^{12}$ dependientes del Consejo Nacional de Educación, quienes brindaban un almuerzo completo, a los cuales se les proporcionaron fondos para su mantenimiento. Dos años después, se organizó la Junta Nacional de "Ayuda al Niño"13, para socorrer al niño en edad escolar con alimentos y vestidos. La Junta estaba constituida por un delegado del Ministerio de Guerra, del de Agricultura, del Banco de la Nación Argentina, del Consejo Nacional de Educación, de la Junta de Ayuda Social y por el presidente del Departamento Nacional de Higiene. El Poder Ejecutivo garantizaba su funcionamiento a través de su mantenimiento económico, el auxilio financiero podía alcanzar hasta un millón de pesos moneda nacional (Novick 1992:107). Tanto el municipio de la ciudad como la provincia de Buenos Aires, en 1937, organizaron una red de comedores a su cargo; en la ciudad, se implementaron los primeros comedores escolares municipales. Al mismo tiempo, la provincia de Buenos Aires, a través del Consejo General de Educación, resolvió fundar un comedor escolar en cada ciudad cabecera de distrito (Britos, O 'D onnel, U galde y Clacheo 2003:15). Paulatinamente, las nuevas instituciones de alimentación escolar, se difundían fuera de la ciudad de Buenos Aires.

12 Medianteley 11.597 del 2 de agosto de 1932.

13 Creado por la ley 11.838 del 22 dejunio de 1934. 


\section{"La adhesión del vecindario": el fundamento de la instalación de los comedores pampeanos}

En los primeros años de la década del 30, el Territorio Nacional de La Pampa fue afectado por una dura crisis agroclimática, una sequía prolongada, que sumada a los cambios en los mercados internacionales de productos primarios, perjudicó en especial a las áreas rurales. Ambos fenómenos generaron una significativa pérdida demográfica. Desde 1935, la población del Territorio que había alcanzado las 175.077 personas según los datos del Censo Territorial del mismo año (Pérez Virasoro 1936); comenzó a disminuir. Así, la población disminuyó hasta llegar a comprender los 167.352 habitantes en 1942 (Ander Egg 1958: 57).

Esta situación agudizó la necesidad de implementar nuevas prestaciones hacia los niños, a partir del modelo instaurado en la ciudad capital del país. Las autoridades educativas otorgaron dentro del entramado de relaciones entre salud y educación, una función muy clara al personal docente, el "primer encargado de hacer cumplir los preceptos higiénicos". Varios quehaceres se incorporaron a la tarea educativa como inherente a ella, que incluían acciones concretas sobre el espacio "velar para que se mantengan las condiciones higiénicas en la escuela, vigilar la aireación del aula", la intervención directa sobre los alumnos al "alejar a los niños sospechosos de enfermedades contagiosas", además de integrar pautas para un mejor desarrollo de la labor pedagógica "evitar el cansancio mental de los niños, mediante la intercalación de recreos oportunos durante las horas de clase, hacer cumplir los preceptos de aseo personal" (Casanave 195:285).

Sin embargo, en las primeras décadas del siglo XX, las funciones sanitarias desarrolladas por los docentes se extendieron más allá de la prevención tradicionalmente realizada a partir de la educación y difusión de principios higiénicos, se sumaron nuevas actividades en torno a la inspección y relevamiento higiénico. Los maestros y las maestras efectuaron distintas tareas acordes a este objetivo, como la inspección de la salud de los escolares en función de la detección de enfermedades, la desinfección de las aulas, la distribución de remedios y la vacunación (Di Liscia 2004).

La segunda línea de acción estimulada fue la acción benéfica hacia los alumnos carenciados. Desde comienzos de la década de 1930, los docentes de Santa Rosa, Trenel y Victorica sostuvieron con 50 cen- 
tavos mensuales de su salario un comedor escolar para más de cincuenta niños ${ }^{14}$. También algunas maestras del interior del Territorio, de la localidad de Anguil, organizaron con las comisiones directivas de las cooperadoras de las escuelas la confección de bombachas, delantales y guardapolvos para los alumnos carenciados ${ }^{15}$. Estas iniciativas individuales se extendieron paulatinamente a otras localidades. $\mathrm{H}$ acia 1935, en el Territorio, funcionaban seis comedores escolares; dos en las principales ciudades, Santa Rosa, la capital y General Pico. Los cuatro restantes en pequeñas localidades del norte territoriano: Anguil, Eduardo Castex, Trenel y Victorica, en ellas, la mayoría de la población escolar provenía, de familias cuya economía dependía, en diferentes grados, de la actividad agrícola-ganadera. El siguiente cuadro describe la incipiente organización existente generada en estas instituciones.

Cuadro 1: Comedores existentes en La Pampa, 1935

\begin{tabular}{|l|l|l|l|}
\hline Localidad & Asociación Responsable & Servicios ofrecidos & Personal existente \\
\hline Santa Rosa & $\begin{array}{l}\text { Sociedad Cooperadora } \\
\text { Escolar } \\
\text { Comedor escolar Infantil } \\
\text { Don Bosco }\end{array}$ & $\begin{array}{l}59.985 \text { comidas } \\
\begin{array}{l}\text { p.395 servicios de } \\
\text { peluquería } \\
139 \text { mamelucos } \\
63 \text { delantales } \\
90 \text { pares de zapatillas }\end{array}\end{array}$ & $\begin{array}{l}\text { Un ecónomo, } \\
\text { un cocinero, un } \\
\text { ayudante, una } \\
\text { celadora }\end{array}$ \\
\hline Anguil & $\begin{array}{l}\text { Cooperadora Escolar } \\
\text { Escuela No 39 }\end{array}$ & $\begin{array}{l}70 \text { comidas diarias en } \\
\text { el período escolar }\end{array}$ & Comisión Especial \\
\hline Eduardo Castex & $\begin{array}{l}\text { Comisión Comedor } \\
\text { Escolar }\end{array}$ & $\begin{array}{l}\text { Invirtió 2.783.95 \$ } \\
\text { durante el año }\end{array}$ & $\begin{array}{l}\text { Un cocinero, un } \\
\text { ayudante, tres } \\
\text { celadores }\end{array}$ \\
\hline General Pico & $\begin{array}{l}\text { Comisión Comedor } \\
\text { Escolar }\end{array}$ & $\begin{array}{l}260 \text { comidas diarias en } \\
\text { período escolar y 230 } \\
\text { en vacaciones }\end{array}$ & $\begin{array}{l}\text { Un ecónomo, } \\
\text { un cocinero, un } \\
\text { ayudante }\end{array}$ \\
\hline Trenes & $\begin{array}{l}\text { Asociación Cooperadora } \\
\text { del Comedor Escolar }\end{array}$ & $\begin{array}{l}31.360 \text { comidas servi- } \\
\text { das durante el año }\end{array}$ & $\begin{array}{l}\text { Una cocinera, un } \\
\text { ayudante, cuatro } \\
\text { celadoras }\end{array}$ \\
\hline Victorica & $\begin{array}{l}\text { Comisión Comedor } \\
\text { Escolar }\end{array}$ & $\begin{array}{l}20.666 \text { comidas servi- } \\
\text { das durante el año }\end{array}$ & $\begin{array}{l}\text { Comisión Especial } \\
\text { de damas }\end{array}$ \\
\hline
\end{tabular}

Fuente: Pérez Virasoro (1936)

14 En los años treinta, los docentes de Santa Rosa, Trenel y Victorica sostuvieron con 50 ctavos mensuales de su sal ario un comedor escolar para más de cincuenta ni ños (ver: AHP, Primera Conferencia Nacional de Asistencia Social, Informe de M. Cabella, 01/09/33).

15 Foja de concepto de la Sra EugeniaS. deAguilera, elaborada por el Director, Lindor Garro de la escuela № 39 del Territorio Nacional de La Pampa, Anguil, 20 de noviembre de 1932. 
Maríaj oséBillorou

Claramente, observamos que el sostén presupuestario de los comedores originalmente a cargo de los docentes, se trasladó primero a los vecinos, con la formación de las Comisiones y Cooperadoras, y luego a las respectivas municipalidades a través del otorgamiento de diferentes tipos de subsidios (D i Liscia 2005).

En Santa Rosa, el Comedor Escolar, a cargo de una Sociedad Cooperadora Escolar dirigida por vecinos de la zona, organizó una estructura de enorme complejidad. Más allá de su función netamente alimentaria, concentrada en la elaboración y en la provisión de las comidas servidas, ${ }^{16}$ se ofrecieron otros servicios: Ia donación de ropas $^{17}$ y peluquería ${ }^{18}$. A ello se sumó la asistencia médica a cargo de un profesional, el Dr. Lorenzano, que trabajaba para la Sociedad Cooperadora, encargado de la revisación periódica de los escolares así como de su asistencia y tratamiento. A pesar de que el número de niños bajo prestación médica no era alto, (ciento diez niños fueron asistidos y veintiocho tratados durante cinco meses en 1933), la incorporación de la asistencia médica dentro de la estructura concebía la acción social ineludiblemente unida a la concepción de salud.

Los maestros habían incorporado claramente los principios del discurso médico que reconoció las dimensiones sociales de ciertas enfermedades y la necesidad de unir atención médica con asistencia social; así, se definió el programa de acción de diversas agencias estatales y de numerosas organizaciones privadas, todas ellas de algún modo involucradas en la lucha contra la tuberculosis, el paludismo, las enfermedades venéreas o la protección de la infancia (Armus y Belmartino 2001:324, Belmartino 2004:272). Los educadores, sostuvieron la importancia de "una alimentación suficiente y adecuada" puesto que era el "puntal y metro" tanto del "desarrollo físico-psíquico del niño" como del "aprovechamiento de la enseñanza". Los docentes, entonces, "en las escuelas" donde surgía el "mal crónico" de la desnutrición, tenían la obligación de "vigilar y tratar de corregir buscándole solución” (Escudero 1936).

16 Entre abril y agosto de 1933, se sirvieron 39.210 comidas. Estadística del movimiento habido del 1 de abril al 31 de agosto de 1933 por la Sociedad Cooperadora Escolar de Santa Rosa La Pampa. Fondo Gobierno Archivo Histórico Provincial.

17 La ropa ofrecida, incluía aquella indispensable para la asistencia escolar, guardapolvos, delantales y zapatillas, como otra vestimenta, tricotas, trajes, cortes de vestidos, medias y otras ropas.

18 Los servicios prestados bajo el concepto de pel uquería, alcanzaron el total de cuatrocientos setenta y cinco prestaciones en el período de abril a agosto de 1933. 
De esta manera, la adhesión a este nuevo ideario de la "medicina social" amplió el ámbito profesional educativo, a través de la gestación de nuevas políticas sociales, funciones sanitarias y asistenciales que, no entraron en contradicción sino que reforzaron el mandato fundacional, eje de la tarea pedagógica, de "educar al soberano". Este propósito de socialización política concebía al ciudadano capacitado para moverse en todos los aspectos de la vida social; por lo tanto, se concebía que la fidelidad a la patria, la moralidad en las costumbres y la virtud ciudadana solían podían concretarse a través de la fortaleza física, el coraje, la destreza y la cultura del trabajo. Por lo tanto, la escuela incorporó la enseñanza de la higiene, la educación física y del trabajo manual con el objetivo de lograr los ideales propuestos (Lionetti 2007).

El gobernador del Territorio, Evaristo Pérez Virasoro, reivindicó la acción de los comedores escolares, durante los años 1936 y 1937, gracias a los cuales "ha mejorado notablemente la salud de los niños favorecidos" (Pérez Virasoro, 1938:18). La pujanza de las nuevas instituciones no sólo se observaba en la estabilidad y permanencia de la mayoría de las fundadas en 1935, sino en la creación de nuevas.

Cuadro 2: Comedores existentes en La Pampa, 1935-1937

\begin{tabular}{|c|c|}
\hline Año $\mathbf{1 9 3 5}$ & Año $\mathbf{1 9 3 7}$ \\
\hline $\mathbf{6}$ comedores en funcionamiento & $\mathbf{1 0}$ comedores en funcionamiento \\
Santa Rosa & Santa Rosa \\
Eduardo Castex & Eduardo Castex \\
General Pico & General Pico \\
Trenel & Trenel \\
Victorica & Victorica \\
Anguil & Bernardo Larroudé \\
& Telén \\
& General Acha \\
& Intendente Alvear \\
& Guatraché \\
\hline
\end{tabular}

Fuente: Pérez Virasoro (1938).

Su vitalidad se debió, además, a la capacidad de respuesta que brindaron a un sector con grandes necesidades económicas de la sociedad pampeana; la cantidad de niños atendidos por los diez comedores, mil setecientos en total, representaba el $6 \%$ de la población 
escolar del Territorio que hacia 1937 alcanzaba los 28.704 niños ${ }^{19}$. El gobernador resaltaba que esta cifra, la población infantil asistente a los comedores, evidenciaba "la importancia y trascendencia de la obra cumplida". Sin embargo, también reconocía que aún se distaba "mucho de alcanzar la proporción debida a la población escolar menesterosa del Territorio". Así, se manifestaba cuán limitada era la asistencia social brindada en las nuevas instituciones a los escolares; no obstante, las autoridades creían en las posibilidades que estas líneas de acción brindaban. Por lo tanto, "la Gobernación" se hallaba "empeñada en ampliar tan útil forma de asistencia social", aunque, los resortes utilizados para generalizar esta política, dependían básicamente de la sociedad civil. En consecuencia, las máximas jerarquías políticas del Territorio, se proponían lograr la expansión de la ayuda social "alentando", en primer lugar, "a las poblaciones que ya lo tienen a perseverar en una obra de tan provechosas consecuencias"; en segundo lugar, a "aquellas donde no existen todavía a que los funden". La función de los poderes públicos, se limitaría a auxiliar en este "esfuerzo" a través de subsidios para "concurrir a su sostenimiento" (Pérez Virasoro 1938:18). A nivel provincial, no se planteaba ni el sostenimiento oficial, y menos aún la obligación estatal para la gestión directa de las instituciones; a diferencia de lo que ocurría en otras jurisdicciones argentinas. D etrás de esta posición, se escondía un Estado territoriano con grandes dificultades financieras y administrativas, imposibilitado de transformarse en el ejecutor y responsable de una política asistencial que implicaba un gran esfuerzo de ingeniería social en un espacio dilatado.

Las diferentes experiencias de las local idades del interior pampeano permiten develar las variadas formas de organización que la sociedad implementó para brindar asistencia a sus niños en edad escolar.

Anguil $^{20}$ era una pequeña localidad situada al este de la capital del Territorio cuya población total (tanto urbana como rural) alcanzaba, para 1935 los 2404 habitantes; pero en el pueblo sólo vivían 1220 pobladores $^{21}$ (Lanzillota 2008). El 1 de agosto 1934, la Cooperadora

19 Circular No 232 del 6 de julio de 1939. Expediente 591-I-1939. Gobernación de la Pampa. Ministerio del Interior. Archivo Histórico Provincial

20 Ubicada a 32 km de Santa Rosa, fuefundada en 1906. Su población mayoritariamente se dedicaba a las actividades agrícolas ganadera.

21 La población que residía permanentemente en el núcleo urbano constituía el 50,7\% de la población del ejido. En la década del treinta, se produjo un mayor crecimiento de la población 
"Patria, Hogar y Escuela" de la Escuela № 39 inauguró un comedor escolar "de las características que ya funcionan en otras localidades"22. Esta Asociación se creó en 1924, a instancias del personal docente con el objetivo de realizar una obra de ayuda social a la población escolar. Diferentes acciones se emprendieron, desde el momento de su creación para responder a las necesidades del alumnado; en primer lugar, la entrega de ropas que implicó su confección, en algunos $\operatorname{casos}^{23}$, para asegurar la concurrencia de los niños a las aulas. En segundo lugar, se organizaron diferentes actividades para colaborar con la correcta alimentación de los escolares: el reparto de leche y bizcochos, el suministro diario de leche y pan a más de trescientos niños. De esta manera, el comedor no se constituyó como una iniciativa aislada, por el contrario, fue el resultado previsto de un proceso iniciado. Sin embargo, la instauración del Comedor, implicó la puesta en marcha de una institución de una mayor complejidad e importancia tanto para la localidad, como para el Territorio.

La Cooperadora, desde sus inicios, se había enfrentado con problemas para institucionalizar su funcionamiento, debido a la escasa participación de los familiares de los alumnos, de esta manera, el personal docente se convirtió en el responsable de dirigir la asociación cooperadora, situación que generó fuertes conflictos dentro del colectivo docente sobre la pertinencia de estas actividades dentro de su perfil profesional.

En el año 1928, ante la renuncia de la presidenta y la tesorera de la Asociación, el maestro Juan E. de Eurasquin, secretario, permaneció como único miembro de la Comisión Directiva. Entonces Eurasquin, frente a la urgente necesidad de iniciar el reparto de leche y bizcochos, propuso que el personal del establecimiento, miembros vocales de la sociedad, tomara las disposiciones necesarias en la reunión de personal. Los docentes, entre ellos el Director, discutieron sobre la "legalidad de la medida" y la necesidad de "ajustarse a términos ju-

urbana en detrimento de la rural, situación que invirtió los patrones de residencia originales de la localidad (Lanzillota 2008).

22 La Arena, 32 de julio de 1934.

23 Las maestras, organizaron especial mente con la comisión di rectiva de la cooperadora, la confección de bombachas, delantales y guardapolvos para los alumnos carenciados en diversas épocas del año escolar. Foja de concepto de la Sra. EugeniaS. deAguilera, elaborada el 20 de noviembre de 1932 por el Director Lindor Garro. Archivo Escolar. Escuela № 39. Anguil. 
rídicos" más allá de la "buena fe y voluntad"24. La participación así como la representación de la Sociedad Cooperadora en los actos escolares, suscitaron, también una serie de inconvenientes y discusiones. Para algunos maestros, los docentes debían convertirse en la voz de la entidad, otros, en cambio, opinaban que los miembros de la asociación debían tener "amplias facultades" para expresar "el sentir de la institución, libre de la acción del maestro ${ }^{25}$.

Otro gran problema fue la obtención de fuentes de financiamiento para sustentar sus acciones, ya que la entidad se financiaba básicamente a través de las cuotas societarias. En 1930, los maestros, preocupados por las carencias material es de sus estudiantes, decidieron establecer una campaña consistente en el dictado de conferencias, para atraer al vecindario; de esta manera, se buscaba acrecentar el número de socios activos de la Cooperadora para garantizar su correcto funcionamiento. Con el mismo objetivo de aumentar el número de asociados, una maestra, la Sra de Migoni, planteó como propuesta "acompañar los maestros a los miembros de la Comisión Directiva a los hogares particulares de los niños", así prestarían "su cooperación en bien de la Sociedad". Sin embargo, esta iniciativa no prosperó ya que la autoridad educativa a cargo de la escuela, solicitó que este "punto de sumo interés" requería un tratamiento "por separado y a estudio $26 "$. Detrás de esa dilación en pos de un análisis más profundo, tal vez, la dirección escolar trataba de evitar que la irrupción de los docentes en los domicilios de sus alumnos, figuras de prestigio y autoridad, fuera percibida como una presión económica en la pequeña localidad.

Aunque también recibía una subvención municipal, para 1938, entre el aporte del municipio y de los socios sólo lograba recaudar la mitad de sus gastos mensuales ${ }^{27}$. De tal manera, necesariamente se vio obligada a "recurrir a otros beneficios"; así, se implementó una eficiente organización para la recaudación de fondos mediante kermeses y bailes populares. El aporte de la comunidad fue crucial para su sostenimiento, "la amplia misión" cumplida por la institución, encontraba

24 Acta № 14. 31 de marzo de 1928. Libros deActas de reuniones de personal docente. Archivo Escolar. Escuela № 39. Anguil

25 Acta № 23. 1 de junio de 1930. Libros de Actas de reuniones de personal docente. Archivo Escolar. Escuela №39. Anguil

26 Acta № 24. 29 de julio de 1930. Libros de Actas de reuniones de personal docente. Archivo Escolar. Escuela №39. Anguil

27 La Arena, 30 de agosto de 1938. 
en el pueblo una amplia respuesta "dada los fines a que destina su producido"28. El gasto mensual de la Cooperadora sumaba los ciento cuarenta pesos, las cuotas y la subvención municipal, sólo, cubrían la mitad de lo necesario para su funcionamiento, setenta pesos.

Sin embargo, se evidencian en el funcionamiento de la Cooperadora las limitaciones que se presentaban para sostener eficientemente en el tiempo un emprendimiento de mayor complejidad asistencial, el comedor escolar. Por lo tanto su vida breve en la ciudad, no se debe a la desaparición de las necesidades alimentarias que lo legitimaron; sino a la propia dinámica política y social de la localidad que no pudo elaborar las estrategias necesarias para sostener una práctica asistencial presentada, tanto por el discurso político, educativo y médico, como modélica.

También era Guatraché un pequeño pueblo ubicado a $160 \mathrm{Km}$. de la capital del Territorio, Santa Rosa. Su población, dedicada a la producción ganadera, explotación forestal y la actividad agrícola, alcanzaba en el radio urbano para 1935, los 1851 habitantes (Ander Egg 1958:66). El proceso de organización del comedor fue similar al de Anguil, el motor de la asistencia escolar lo constituyó la Asociación Cooperadora de la Escuela № 60. Aunque desde 1919 se buscaba conformarla, recién pudo instituirse el 14 de septiembre de 1930, con el objetivo de lograr un mejor desarrollo físico e intelectual de la infancia. En pos de este objetivo, efectuó actividades que aseguraran la asistencia escolar de los niños más necesitados; suministró alimentos complementarios (el pan lácteo) y distribuyó en forma permanente ropa, calzado y útiles escolares.

El vecindario apoyó estas iniciativas, "compenetrado de la bondad, de la obra que realiza no ha regateado su apoyo económico y moral en ninguna circunstancia", a las que se sumaba la colaboración permanente desde 1933 de las autoridades municipales; así como el "entusiasmo y el desinterés de las personas que han actuado en las distintas comisiones directivas"29.

La necesidad de sistematizar y generalizar la ayuda alimentaria, en gran medida como respuesta frente a la crisis agrícola y al consiguiente éxodo poblacional, provocó la búsqueda de una institución permanente: el Comedor Escolar. Los miembros de la Comisión Di-

28 La Arena, 30 de agosto de 1938.

29 El Imparcial, 16 de mayo de 1944. 
rectiva recurrieron a las autoridades comunales para conseguir una subvención mensual que posibilitara su surgimiento. El municipio colaboró con la adjudicación de una partida mensual de trescientos pesos moneda nacional de marzo a noviembre para asegurar su funcionamiento durante el año escolar ${ }^{30}$. Este subsidio fue central para la instalación de la nueva institución; así, el 31 de marzo de 1936 se inauguró con la presencia del Inspector seccional señor Horacio Rotier, las autoridades locales, los maestros de las escuelas de la zona y los vecinos.

El sostenimiento del Comedor por el municipio no se limitó únicamente al auxilio financiero, el médico municipal, el Dr. Jacobo Bohoslavsky, fue el responsable de la asistencia médica de los escolares concurrentes. Para ello, ideó un sistema especial de seguimiento mediante fichas de control en las que mes a mes comprobaba el estado físico de cada alumno. Así, se revela la mayor complejidad organizativa alcanzada por esta institución gracias al financiamiento municipal sostenido.

La presencia del médico manifestaba la adopción de un paradigma de asistencia médica-social que iba más allá del simple auxilio; estas ideas y prácticas, paulatinamente, se implantaron en la sociedad pampeana. Los diarios construyeron en su discurso un modelo de organización para la asistencia alimentaria; por lo tanto, el comedor infantil era "una empresa mucho más seria y delicada de lo que a primera vista pudiera parecer". En tanto caracterizado como una "institución humana de ayuda social", la organización debía adquirir ribetes de perfección "para que el comedor cumpla debidamente con su cometido". Esta estructura debía contar, de manera indispensable, con la asesoría de "un médico" quien era el responsable reconformación de "la ficha individual de cada niño, con todos los datos que aquel crea necesario", de "exigir periódicamente se controle el peso para tomar medidas oportunas; en igual forma se procederá con la estatura". Distinguía, con lucidez, que su misión no era brindar "sólo comida a los niños, de ser así sólo sería un 'comedero'". Su definición en tanto Comedor Escolar, lo trasformaba en "una institución del estado destinada a formar una generación fuerte para que lo sea también espiritualmente" ${ }^{\prime \prime}$.

30 Resolución municipal del 27 de diciembre de 1935. Actas del Concejo Municipal. Municipalidad de Guatraché

31 La Arena, 15 de julio de 1939. 
La organización de los comedores escolares, en ambas localidades, respondió a una matriz común; la necesidad de brindar auxilio y ayuda a una de los sectores más vulnerables, los niños a partir de los ejemplos internacionales y nacionales. La alimentación, necesidad básica que implica la supervivencia tanto individual como colectiva, recibió una atención primordial. El funcionamiento de los organismos estuvo a cargo principalmente de los docentes que coordinaron las acciones y movilizaron a toda la comunidad. El éxito de las nuevas prácticas se debió, en gran medida, a su transformación en iniciativa pública que congregara tras si a toda la población. El apoyo municipal, fue crucial para modificar una iniciativa de un grupo en una política estatal.

\section{Algunas preguntas finales: ¡la acción debe iniciarse de inmediato?}

Finalmente, las diferentes propuestas implementadas para mejorar la salud de los escolares evidenciaron su impacto en la sociedad; así, el Estado nacional incorporó el tema en su agenda a partir de la generación de políticas nacionales. Para centralizar y organizar, la protección y asistencia de los alumnos, en 1938, el Estado instituyó la Comisión Nacional de Ayuda Escolar compuesta por el M inisterio de Justicia e Instrucción Pública, el Presidente del Consejo Nacional de Educación y el Presidente del Departamento Nacional de Higiene. Así, sancionó el 3 de mayo de 1938 la ley 12558, "Protección a los niños en edad escolar. Instituciones complementarias de la educación común" que estableció los fines de esta Comisión: el cuidado de la salud física y moral de la niñez en edad escolar, especialmente en las provincias y en los territorios nacionales.

Los fundamentos del decreto presidencial que comenzó el trámite legislativo, sostenían que la acción debía "iniciarse de inmediato sin encararla como tarea de caridad sino en su verdadero concepto de imperativo social". La urgencia se imponía en tanto "la situación" en que se encontraba "la infancia en las ciudades, villas y campañas de las provincias y territorios", pues de otra manera las escuelas "recibirán un número reducido de alumnos, en condiciones tales, que sólo una 
parte de ellas alcanzará a salir de analfabetismo, pero la mayoría con una salud tan precaria que será fatal la degeneración de la raza"32.

Los instrumentos seleccionados, en pos de la consecución de los objetivos propuestos, fueron: la atención a domicilio y en consultorio, la oferta de servicios públicos (ambas actividades gratuitas), el examen y la asistencia de los niños en los locales de las escuelas, la difusión de instrucciones sobre enfermedades, especialmente regionales y su profilaxis y la distribución gratuita de medicamentos (Novick 1992:107).

D os instituciones recibieron especial atención como medios esenciales para atender las necesidades de la población escolar: los comedores escolares y las escuelas hogares. El artículo 5 de la ley establecía las facultades de la Comisión, ya que la asistencia se brindaría a través del entramado institucional dependiente de numerosas jurisdicciones: gobernadores de provincia, municipios, instituciones nacionales y particulares. Así, se subvencionarían los diferentes tipos de asociaciones existentes (cooperadoras escolares, cooperadoras regionales, organizaciones constituidas por padres o vecinos, amigos de la educación) a la vez que se propendería a su formación. Sin embargo, se establecieron ciertos requisitos para su reconocimiento: la existencia de fondos sociales propios, la organización de la asistencia médica y la ayuda en forma de subsidio, remedios, provisión de víveres y ropa. Ú nicamente donde las necesidades escolares lo requiriesen, según el artículo 6 de la ley, la Comisión en representación del Estado, asumiría la responsabilidad de proveer de alimentos a los niños en comedores escolares.

De esta manera, la resolución de la instalación de seiscientos comedores a su cargo en todo el país ${ }^{33}$ pareció convertirse para la sociedad pampeana, en la solución frente a la situación de los vecindarios "azotados por la crisis" que se hallaban "imposibilitados de contribuir a su sostenimiento". A partir de 1938, se generalizó la situación cada vez más acuciante de "centenares de niños que no pueden concurrir a las aulas por falta de ropa y de útiles y los hay, esto es la más triste y los más grave, y en cantidades, que no pueden asistir porque carecen de alimentos" ${ }^{\prime \prime 4}$. Con la creación de la Comisión Nacional de Ayuda Escolar del Consejo Nacional de Educación, la comunidad pampeana esperaba recibir aportes estatales para su mantenimiento.

32 Decreto 3607, 3 de mayo de 1938 Página 11.

33 La Capital, 4 de mayo de 1938.

34 La Capital, 18 de mayo de 1939. 
Sin embargo, apenas conocido el presupuesto disponible (sólo dos millones de pesos argentinos) para proveer ropa, medicamentos y alimentos; se evidenciaron las limitaciones de la nueva estructura. La suma dispuesta por el Estado era "algo", pero si se estimaba "con algún reposo el destino que se les ha señalado", se descubría que era "muy poca cosa para el caso". La opinión se basaba en que la cantidad de "dos millones para vestir, calzar, darles de comer y medicinas" se convertía en "poco dinero" 35 . A esto se sumaba la lentitud de la implementación de las políticas nacionales que requería de una sucesión de trámites burocráticos (aprobación del pliego de condiciones para su instalación, licitación para la adquisición del material necesario) realizados por el Consejo Nacional de Educación, organismo colegiado quien aplazaba aún más el proceso. Un año después, en mayo de 1939, la acción de la Comisión "ha llegado a algunos comedores escolares, pero sólo a algunos" ${ }^{36}$, no se había efectivizado en el Territorio "con la urgencia37" que se la necesitaba. Esta situación provocó la reacción de los poderes locales a partir de la gestiones ante la Comisión de Ayuda Escolar tanto del gobernador del Territorio, Evaristo Pérez Virasoro como del juez letrado Dr. Millán.

Así, las políticas nacionales generaron más preguntas que respuestas efectivas. La instalación de comedores escolares respondía a los lineamientos internacionales a la vez que se enlazaba en la nueva concepción de salud positiva y medicina social. Además, recogía una serie de experiencias llevadas adelante en diferentes jurisdicciones con un cierto grado de éxito, debido en gran medida del apoyo y colaboración de la sociedad que reconocía la importancia de estas nuevas instituciones para la consecución de la salud colectiva. Sin embargo, la pretensión de crear una red asistencial de comedores que cubriera todo el país se presentaba como un objetivo demasiado ambicioso para el financiamiento disponible. Al mismo tiempo, la exigua estructura edilicia, los pocos recursos humanos disponibles, insuficiencia que se acentuaba para los profesionales médicos, provocó que la efectiva implementación institucional recayera en asociaciones de la sociedad civil. Los destinatarios principales de la política alimentaria lo constituyeron comunidades atravesadas por la crisis económica, como

35 La Capital, 10 de mayo de 1938.

36 La Capital, 18 de mayo de 1939.

37 La Capital, 19 de mayo de 1939. 
Maríaj oséBillorou

lo demuestra el ejemplo del Territorio Nacional de La Pampa. De esta manera, las posibilidades reales de convertirse en gestores dinámicos, fueron ilusorias. La Comisión Nacional de Ayuda Escolar, desde sus inicios, encontró fuertes limitaciones a su accionar que determinaron, en gran medida, su efímera existencia institucional, aun más que la dinámica política argentina.

\section{Fuentes}

BAZÁN, Florencio y RUIZ MORENO, Guido (1939) "Comedores Escolares", en:Boletín delaO FICIN A SAN ITARIA PAN AM ERICANA. Año 18, № 12, Diciembre de 1939.

CABELLA, Mario (1933) Primera Conferencia Nacional de Asistencia Social, Informe del Director de la Asistencia Pública, Dr. Mario Cabella, del 1 de septiembre de 1933. AHP. Santa Rosa.

CASANAVE, Antonio (1950) Higiene. Buenos Aires, Editorial Luis Lasserre, 70 edición.

DIARIO LA ARENA, Archivo del Diario La Arena, Santa Rosa. Serie: 1933-1946.

DUVAL, M iguel (1946) Memoria Gráfica. Período de Gobierno 19391945, Santa Rosa, G obernación de la Pampa, República Argentina, Ministerio del interior.

DUVAL, Miguel, (1941) M emoria presentada al Superior Gobierno de la Nación, Período: 1940-1941, Santa Rosa, Talleres Gráficos de la Gobernación de la Pampa.

ESCUDERO, Dolores O. (1936) "El alimento en las escuelas" en: La O bra. Revista Q uincenal de Educación. Tomo XVI. № 14. O ctubre 10 de 1936.Año XVI № 285. Páginas 670-671.

ESCUDERO, Pedro (1938-1939) "La alimentación de la familia en Buenos Aires", en: Boletín del Instituto Nacional de Nutrición.

ESCUDERO, Pedro (1940) "La tercera Conferencia Internacional de la alimentación. Síntesis de sus deliberaciones, conclusiones que se desprenden", en: Boletín de la Oficina Sanitaria Panamericana. Año 19 Nㅇ 4, Abril de 1940. 
FONDO GOBIERNO, AHP, Santa Rosa, N otas e informes. Serie: 1933-1946.

GARRO, Lindor (1932) Foja de concepto de la Sra. Eugenia S. de Aguilera, elaborada por el Director de la Escuela $\mathrm{N} 039$ del Territorio Nacional de La Pampa, Lindor Garro, el 20 de noviembre de 1932. Archivo Escolar, Escuela $\mathrm{N} \cong$ 39, Anguil.

LIBROS DE ACTAS DE REUNIONES DE PERSONAL DOCENTE. Archivo Escolar. Escuela $\mathrm{N} 0$ 39. Anguil.

OLIVIERI, Enrique (1931) "Alimentación de los escolares en Buenos Aires", en: Boletín de la Oficina Sanitaria Panamericana. Año 10, № 7, Julio de 1931.

PÉREZ VIRASO RO, Evaristo (1936) Memoria presentada al Superior Gobierno de La Nación año 1935, Santa Rosa, Ministerio del Interior, Talleres Gráficos de la Provincia de La Pampa.

PÉREZ VIRASO RO, Evaristo (1938) Memoria presentada al Superior Gobierno de La Nación años 1936-1937, Santa Rosa, Ministerio del Interior, Talleres Gráficos de la Provincia de La Pampa.

SO CIED AD CO O PERAD O RA ESCO LAR DESANTA RO SA LA PAM PA (1933) Estadística del movimiento habido del 1 de abril al 31 de agosto de 1933. Fondo Gobierno, AHP, Santa Rosa.

\section{Referencias bibliográficas}

ANDER EGG, Ezequiel (1958) La Pampa. Esbozo preliminar para un estudio de su estructura socio-económico. Volumen 1. Demografía. Santa Rosa, Gobierno de la Provincia de la Pampa.

ARMUS, Diego (2000) "El descubrimiento de la enfermedad como problema social" en LOBATO, Mirta (dir.) El progreso, la modernización y sus límites (1880-1916), N ueva Historia Argentina, tomo 5, Buenos Aires, Editorial Sudamericana, pp. 507-550.

ARM US, Diego (2007) La ciudad impura. Salud, tuberculosis y cultura en Buenos Aires, 1870-1950, Buenos Aires, Edhasa.

ARMUS, Diego y BELMARTINO Susana (2001) "Enfermedades, médicos y cultura higiénica", en: A. CATTARUZZA (dir.) Crisis económica, avance del estado e incertidumbre política (1930- 
Maríaj oséBillorou

1943), N ueva Historia Argentina tomo 7, Buenos Aires, Editorial Sudamericana, pp. 283-329.

BARONA VILAR, Joseph Lluis (2008) "La génesis de una fisiología de la nutrición. El impuslo de la sociedad de las Naciones en los años 1930", en: La experiencia de enfermar en perspectiva histórica. Actas del XIV Congreso de la Sociedad Española de Historia de la Medicina, U niversidad de G ranada, Granada, junio de 2008.

BELMARTINO, Susana (2004) "La emergencia del estado social en la Argentina: construcción de nuevas relaciones Estado/sociedad en salud", en A. ÁLVAREZ, MOLINARI, I. y REYNOSO, D. (ed.) Historias de enfermedades, salud y medicina en la Argentina del siglo XIX-XX, Mar del Plata, U niversidad Nacional de Mar del Plata, pp. 257-289.

BILLOROU, María José (2008) "Por el impulso de un pueblo en movimiento: los servicios de salud pública", en A. M. RODRÍGUEZ et al Esa antigua tierra que somos. Guatraché 1908-2008, Municipalidad de Guatraché-U niversidad Nacional de La Pampa. Buenos Aires, Miño y Dávila, pp. 373-390.

BRITOS, S., O' DONCEL, A., UGALDE, V. y CLACHEO, R. (2003) Programas alimentarios en Argentina, Buenos Aires, Centro de Estudios sobre nutrición infantil.

CARLI, Sandra (2005) “Niñez, Pedagogía y política. Transformaciones de los discursos acerca de la infancia en la historia de la educación argentina entre 1880 y 1955", Buenos Aires, Editorial Miño y Dávila.

DI LISCIA, M aría Sil via (2004) “M édicos y maestros. Higiene, eugenesia y educación en Argentina, 1880-1940", en: G. SALTO y M. S. DI LISCIA (ed.) Medicina y educación en la Argentina: imágenes y prácticas (1880-1940), Buenos Aires, EdulPam, pp.37-64.

DI LISCIA, María Silvia (2005) “Colonias y escuelas de niños débiles. Los instrumentos higiénicos para la eugenesia. Argentina, 19101940", en: M. S. DI LISCIA, María Silvia y E. BOHOSLAVSKY (2005) (ed.) Instituciones y formas de control social en América Latina, 1840-1940. Una revisión, Buenos Aires, EdU LPam-U N GSPrometeo Ediciones, pp. 93-113.

DOBA, Claudia y SÁNCHEZ, Laura (2008) “La educación. Un sueño maravilloso que irradia como un alba lejana en la conciencia 
dolorida de la muchedumbre", en: A. M. RODRÍGUEZ et al Esa antigua tierra que somos. Guatraché 1908-2008, Municipalidad de Guatraché-U niversidad N acional de La Pampa, Buenos Aires, Miño y Dávila, pp. 421-458.

GARCÍA GONZÁLEZ, Armando y Raquel ÁLVAREZ PELÁEZ (1999) En busca de la raza perfecta. Eugenesia e higiene en Cuba (18981958), Madrid, Consejo Superior de Investigaciones Científicas.

LANZILLOTA, María (2008) "La población en cifras", inédito.

LAVRIN, Asunción (1998) Women, Feminism \& Social Change in Argentina, Chile \& U ruguay 1890-1940. Lincoln and London, University of N ebraska Press.

LIONETTI, Lucía (2007) La misión política de la escuela pública: educar al ciudadano de la república (1870-1916). Buenos Aires, Miño y Dávila.

M IRANDA, Marisa y VALLEJO, Gustavo (comp.) (2005) Darwinismo social y eugenesia en el mundo latino, Buenos Aires, Siglo XXI de Argentina Editores.

NOVICK, Susana (1992) Política y población. Tomo 1. Argentina 1870-1989, Buenos Aires, Centro Editor de América Latina.

SOSA DE NEWTON, Lily (1986) Diccionario biográfico de mujeres argentinas. Buenos Aires, Editorial Plus UItra.

STEPAN, Nancy Leys (1991) "Hour of eugenics": Race, Gender and Nation in Latin America. Ithaca, Cornell U niversity Press.

ZAPIOLA, Ma. Carolina (2006) “ ¿Es realmente una colonia? ¿Es una escuela? ¿Qué es? Debates parlamentarios sobre la creación de instituciones para menores en la Argentina, 1875-1890", en: D. LVOVICH y J. SURIANO, Las políticas sociales en perspectiva histórica. Argentina 1870-1952, Editorial Prometeo, Buenos Aires, pp. 65-88.

\section{Resumen}

Este trabajo busca examinar el surgimiento de una red de instituciones, los comedores escolares en el Territorio Nacional de La Pam- 
pa en la década de 1930, cuyo accionar se basó en la protección y la defensa de la infancia más vulnerable. El análisis de este proceso, permite develar el protagonismo de los distintos agentes estatales, las relaciones suscitadas entre las diferentes jurisdicciones - nacional, provincial y municipal- así como el papel de la comunidad en la ejecución concreta de políticas públicas.

Palabras clave: Protección a la infancia, políticas sociales, alimentación, Estado.

\section{The raising of welfare kitchens in La Pampa during the crisis.} Summary

This paper attempts to examine the raising of a network of institutions, comedores escolares [welfare kitchens] in the National Territory of la Pampa during the 1930's, whose action was based upon the protection and defense of the most vulnerable infants. The analysis of this process shows the leading role of different state agents, the relationships that took place among different jurisdictions such as national, provincial and communal ones, as well as the role of community in the concrete implementation of public policies.

Key words: Infancy protection, social policies, nourishment, State.

Recibido: 13/08/08; aceptado: 21/10/08. 